\title{
INFLUÊNCIA DAS VARIÁVEIS AMBIENTAIS NO PROGRESSO DA ANTRACNOSE DO FEIJOEIRO E EFICIÊNCIA DE TIOFANATO METÍLICO + CLOROTALONIL NO CONTROLE DA DOENÇA ${ }^{1}$
}

\author{
Influence of the environmental variables in the progress of anthracnose of bean and efficiency \\ of thiophanate methyl + chlorothalonil in the control of the disease
}

\author{
Alvanir Garcia ${ }^{2}$, Paulo Estevão de Souza ${ }^{3}$, Edson Ampélio Pozza ${ }^{3}$, Florisvalda da Silva Santos ${ }^{4}$
}

\begin{abstract}
RESUMO
Em Minas Gerais a antracnose destaca-se como uma das principais doenças foliares do feijoeiro comum, pela sua ocorrência em diversas épocas de plantio e redução na produção. No presente trabalho avaliou-se a ocorrência, o progresso da doença e a eficiência do controle químico da antracnose. Foram avaliadas parcelas com e sem tratamento fungicida (Tiofanato metílico + Clorotalonil, 240 + 600g i.a./ha) em cinco épocas de avaliação da doença em 24 plantios da cultivar carioca, de 04/96 à 03/97. Não se constatou a ocorrência da antracnose no período de fevereiro a março de 1997 . O tratamento com fungicida resultou em menor severidade da doença e maior produção, principalmente nos meses de maior severidade dela. A severidade da doença correlacionou-se com as variáveis ambientais de temperatura máxima e mínima e umidade relativa aos 43, 57 e 71 dias após a emergência. Houve correlação negativa entre severidade da doença e produtividade do feijoeiro.
\end{abstract}

Termos para indexação: Phaseolus vulgaris L., Colletotrichum lindemuthianum, epidemiologia.

\section{ABSTRACT}

In Minas Gerais the anthracnose is one of the most important leaf diseases of the common bean due to occur at various planting time and to reduce the production. The present experiment was performed aiming to evaluate occurrence, progress of the disease and the efficiency of fungicide on the control of bean anthracnose. Plots with and without fungicide treatment (Thiophanate methyl + Chlorothalonil, $240+600 \mathrm{~g}$ a. i./ha) were evaluated in five times of evaluation during 24 sowing times of bean cultivar Carioca, between April/96 and March/97. The occurrence of the anthracnose was not verified during february and march of 1997. Treatment with fungicide resulted in the lower disease severity and higher yield, mainly in the months of higher severity of the disease. There was significant correlation between the severity and the maximum and minimum temperature and relative humidity 43, 57 and 71 days after emergency. There was a negative correlation between severity of the disease and yelds.

Index terms: Phaseolus vulgaris L., Colletotrichum lindemuthianum, Epidemiology.

(Recebido em 15 de julho de 2005 e aprovado em 26 de abril de 2007)

\section{INTRODUÇÃO}

O feijão figura tradicionalmente no Brasil como ingrediente básico na alimentação da população. Registrase um consumo per capita em torno de $17 \mathrm{Kg} / \mathrm{hab}$./ano, sendo Minas Gerais um dos principais produtores dessa leguminosa, cuja produtividade média encontra-se em torno de $1.050 \mathrm{Kg} / \mathrm{ha}$ (AGRIANUAL, 2004). Por ser cultivada durante todo o ano e numa diversidade de ecossistemas, a cultura do feijão está exposta a uma série de fatores capazes de ocasionar perdas na produção. Dentre eles, encontram-se as doenças foliares quase sempre associadas ao pequeno rendimento da cultura e à baixa qualidade sanitária e comercial do produto (NUNES \& BERGAMIN FILHO, 1996).

A antracnose, cujo agente etiológico é o fungo Colletotrichum lindemuthianum (Sacc. \& Magn.) Bri. \& Cav., destaca-se como uma das doenças mais importantes do feijoeiro pelo por ocorrer em diversas épocas de plantio e pela redução que ocasiona na produtividade. As lesões podem afetar desde cotilédones e hipocótilo de plântulas infectadas, levando-as à morte, até caule, pecíolos, limbo foliar e vagens de plantas adultas, comprometendo as sementes (POMPEU et al., 1992; RAVA et al., 1994).

\footnotetext{
Parte da dissertação de mestrado do primeiro autor, apresentada à UFLA, para obtenção do grau de Mestre em Agronomia - Área de concentração em Fitopatologia.

${ }^{2}$ Engenheiro Agrônomo, Mestre - Embrapa Rondônia - BR 174, KM5,5 - Cx. P. 406 - 78900-970 - Porto Velho, RO - alvanir@cpafro.embrapa.br

${ }^{3}$ Doutores, Professores - Departamento de Fitopatologia/DFP - Universidade Federal de Lavras/UFLA - Lavras, MG - pauleste@ufla.br; eapozza@ufla.br ${ }^{4}$ Doutoranda em Agronomia - Departamento de Ciências Humanas/DCH - Universidade do Estado da Bahia/UNEB - Rodovia $242, \mathrm{Km} 04$ s/n - $47800-000$ Barreiras, BA - flvsantos@yahoo.com.br
} 
O fungo sobrevive em restos de cultura e sementes contaminadas, sendo essas suas vias de sobrevivência e disseminação mais importantes (HALL, 1994). O progresso da doença é maior em temperaturas entre 13 e $27^{\circ} \mathrm{C}$, sendo a condição ótima a $17^{\circ} \mathrm{C}$ e umidade relativa acima de $91 \%$ (PRIA et al., 2003; RAHE \& KUC, 1970; SCHWARTZ \& GALVEZ, 1980) aliadas à precipitação freqüente (ARAYA et al., 1987). Os conídios germinam em 6 a 9 h sob condições de favoráveis, penetram mecanicamente pela cutícula e epiderme do hospedeiro e as lesões são visíveis a partir de 6 dias, após o início da infecção. Períodos de molhamento foliar entre 18 e $24 \mathrm{~h}$ aumentam acentuadamente a severidade da antracnose (PRIA et al., 2003). Chuvas e ventos constantes são essenciais para disseminar os conídios do patógeno e proporcionar maior taxa de progresso da epidemia (SCHWARTZ \& GALVEZ, 1980). Por requerer essas condições ambientais para desenvolvimento da epidemia, pode-se inferir que a antracnose não ocorre durante todo ano agrícola. E, assim, uma análise temporal pode oferecer conclusões importantes sobre qual a melhor variedade a ser plantada ou qual o momento exato para pulverização (BERGAMIN FILHO et al., 1995).

O emprego de cultivares resistentes à doença é a forma mais prática e econômica de controle (NUNES \& BERGAMIN FILHO, 1996), no entanto a variabilidade patogênica de $C$. lindemuthianum (RAVA, 2002) dificulta a obtenção das mesmas pelos programas de melhoramento genético do feijoeiro, tornando necessário o uso de fungicidas para minimizar as perdas. $\mathrm{O}$ uso de fungicidas também é uma medida complementar que contribui para a durabilidade da resistência de uma cultivar ao diminuir a pressão de seleção no patógeno.

As perdas no cultivo do feijoeiro podem ser da ordem de $100 \%$, quando se plantam sementes infectadas sob condições favoráveis à maior severidade da doença (CHAVES, 1980). Nunes \& Bergamin Filho et al. (1996) não observaram correlação entre a severidade da doença e a produção encontrando, porém, correlação linear positiva e significativa entre as variáveis absorção da área foliar sadia (HAA) e duração da área foliar sadia (HAD), e a produção. Talamini (2003) também não observou correlação significativa entre a área abaixo da curva de progresso da incidência e da severidade da doença com a produção de grãos de feijão, nas duas épocas de plantio estudadas.

De acordo com o exposto acima, conduziu-se este trabalho para analisar o progresso da antracnose do feijoeiro e a eficiência do controle químico.

\section{MATERIAL E MÉTODOS}

Instalação e condução do experimento - Instalou-se o experimento de campo, em latossolo roxo distrófico, na área experimental do Departamento de Agricultura da Universidade Federal de Lavras - UFLA, localizada a $21^{\circ} 14^{\prime}$ de latitude sul, $45^{\circ}$ de longitude oeste de Greenwich e 900 metros acima do nível do mar, no município de Lavras, MG.

$\mathrm{O}$ delineamento experimental utilizado foi o de blocos casualizados, com quatro repetições, com os tratamentos em esquema fatorial $(2 \times 5)$, sendo o fator 1 , com e sem pulverização de fungicida e fator 2 , cinco épocas de avaliação da doença, as quais foram aos 15, 29, 43, 57 e 71 dias após a emergência (d.a.e) do feijoeiro, correspondendo aos estádios fenológicos de pré-floração, floração, formação da vagem, enchimento de vagem e maturação do hospedeiro, respectivamente. $\mathrm{O}$ experimento foi repetido 24 vezes, a partir de 06/04/96, de 15 em 15 dias. As parcelas que receberam fungicida foram pulverizadas com a mistura Tiofanato metílico + Clorotalonil, na dose de $240+600 \mathrm{~g}$ de ingrediente ativo (i.a.)/ha para o controle da antracnose. Fez-se a primeira aplicação preventiva 30 dias após o plantio e a segunda e a terceira aplicação a intervalos de 15 dias, a partir da primeira.

Utilizou-se a cultivar carioca, suscetível à doença, por ser a mais utilizada na região e pela maior área cultivada no Estado. Os ensaios foram conduzidos sob condições naturais de infecção da doença, com irrigação por aspersão apenas nos períodos considerados secos na região de Lavras (junho, julho e agosto). Para o controle das ervas daninhas, realizou-se a capina manual. Como adubação de plantio utilizaram-se $400 \mathrm{Kg} / \mathrm{ha}$ da fórmula 04-14-08. O controle de pragas do solo foi feito com o inseticida Carbofuran, na dose de $10,5 \mathrm{Kg}$ i.a./ha, no sulco de plantio. Para o controle das pragas da parte aérea, utilizou-se o inseticida Deltametrin (12,5 g i.a./100 litros de água).

Ocorrência e Progresso da doença e Produção Foi avaliada a ocorrência, incidência e severidade da antracnose, bem como a eficiência do tratamento com fungicida e o rendimento de grãos no final do ciclo, após as plantas atingirem a maturação fisiológica.

Para a avaliação das doenças foram marcadas aleatoriamente 10 plantas por parcela. Inicialmente avaliouse a ocorrência da doença atribuindo-se o valor 1, quando foram constatados sintomas da doença na planta e 0 , na ausência de sintomas. Logo após avaliou-se a incidência, pelo número de plantas com sintomas, e a severidade, conforme a porcentagem de área foliar lesionada, com o auxílio de uma escala diagramática (EMBRAPA, 1981). A incidência e a severidade da antracnose foram determinadas, calculando-se a média dos 24 plantios. 
Análise dos dados - Os valores médios da incidência e severidade da doença foram utilizados para plotar as curvas de progresso da doença em função das épocas de avaliação da doença e submetidos à análise de regressão para escolha do modelo polinomial de melhor ajuste, baseando-se no maior valor do coeficiente de determinação $\left(\mathrm{R}^{2}\right)$ e significância estatística do ajuste. Os valores de severidade ao longo do tempo foram transformados em área abaixo da curva de progresso da doença (AACPD), conforme Campbell \& Madden (1990) e, em seguida, essa variável foi submetida à análise de variância.

Os valores médios de produção por hectare foram submetidos à análise de correlação com a severidade da doença, nas diferentes épocas de avaliação. A temperatura e a umidade relativa, obtidas pelo registro em termohigrógrafo instalado no local do experimento, bem como a pluviosidade obtida na estação agrometeorológica da UFLA, foram correlacionadas com a severidade da antracnose.

\section{RESULTADOS E DISCUSSÃO}

A ocorrência da antracnose foi constatada desde a primeira até a vigésima segunda época de semeadura, no período de maio/96 a janeiro/97. Portanto, não ocorreu somente em fevereiro e março de 1997.

Houve aumento na severidade da doença, embora descontínuo, a partir do primeiro plantio até o décimo plantio (08/96), quando a doença atingiu a máxima severidade (Figura 1B). A temperatura média em torno de $17^{\circ} \mathrm{C}$ favoreceu o progresso da antracnose a partir de junho quando a severidade atingiu valores acima de $10 \%$. A partir de setembro a severidade permaneceu em torno de $20 \%$ e se manteve elevada até janeiro. Nesse período verificouse aumento crescente na média das temperaturas máximas. Conforme Pria et al. (2003), o período de incubação da antracnose é reduzido a $25^{\circ} \mathrm{C}$. Como a temperatura atingiu valores entre 23 e $24^{\circ} \mathrm{C}$, durante o período de execução do presente trabalho, isso possivelmente encurtou o período de incubação da doença, aumentando o número de ciclos do patógeno sobre o hospedeiro e, consequentemente, elevando a severidade da doença aos valores máximos equivalentes a $35 \%$.

A pluviosidade média e a umidade relativa mínima não apresentaram correlação com a severidade da doença nas cinco épocas de avaliação (Tabela 1). As demais variáveis apresentaram correlação significativa depois dos 43 dias após a emergência. A correlação foi positiva para a umidade relativa e severidade aos 43 e 57 dias após a emergência das plantas. Mas, aos 71 dias, já ao final do ciclo do feijoeiro a correlação foi negativa, possivelmente porque apesar da umidade relativa continuar favoravelmente elevada, houve redução na quantidade de doença estimada, possivelmente pela redução na disponibilidade de tecido sadio para novas infecções. A severidade média da doença foi estimada para as folhas presentes na planta, não se considerando aquelas já caídas.

O decréscimo na severidade da doença, observado após janeiro de 1997, reduzindo-se drasticamente a zero nos dois últimos plantios, coincidiu com o pouco volume de chuvas, ausência de irrigação neste período e aumento na temperatura com máximas acima de $36{ }^{\circ} \mathrm{C}$ (Figura 1). Essas condições verificadas em janeiro, com queda brusca na curva de progresso da antracnose, proporcionaram um ambiente desfavorável à doença e corrobora o efeito

Tabela 1 - Coeficientes de correlação entre severidade média da antracnose em cinco épocas de avaliação e temperatura máxima (Tmax), temperatura mínima (Tmin), umidade relativa do ar máxima (Urmax), umidade relativa do ar mínima (Urmin) e volume pluviométrico (Pluv), ocorridas durante os quinze dias antes das avaliações.

\begin{tabular}{cccccc}
\hline \multirow{2}{*}{ Variáveis } & \multicolumn{4}{c}{ Coeficientes de correlação } \\
\cline { 2 - 5 } & $15^{\mathrm{I}}$ & 29 & 43 & 57 & 71 \\
\hline Tmax & $-0,11^{\mathrm{NS}}$ & $-0,32^{\mathrm{NS}}$ & $-0,49^{* *}$ & $-0,52^{* *}$ & $-0,45^{*}$ \\
Tmin & $-0,15^{\mathrm{NS}}$ & $-0,26^{\mathrm{NS}}$ & $-0,39^{*}$ & $-0,44^{* *}$ & $-0,41^{*}$ \\
URmax & $0,16^{\mathrm{NS}}$ & $0,17^{\mathrm{NS}}$ & $0,33^{*}$ & $0,30^{*}$ & $-0,38^{*}$ \\
URmin & $0,01^{\mathrm{NS}}$ & $0,04^{\mathrm{NS}}$ & $0,11^{\mathrm{NS}}$ & $0,03^{\mathrm{NS}}$ & $-0,03^{\mathrm{NS}}$ \\
Pluv & $-0,17^{\mathrm{NS}}$ & $-0,13^{\mathrm{NS}}$ & $-0,01^{\mathrm{NS}}$ & $-0,07^{\mathrm{NS}}$ & $-0,13^{\mathrm{NS}}$ \\
\hline
\end{tabular}

NS = não significativo. $*$ = significativo a $5 \%$ de probabilidade pelo teste de $\mathrm{F} . * *=$ significativo a $1 \%$ de probabilidade pelo teste de F. ${ }^{1}=$ Dias após a emergência das plântulas. 
limitante da temperatura na curva de progresso da doença, confirmando observações feitas por Rahe \& Kuæ (1970). De acordo com os autores, ocorre diminuição do número e do tamanho das lesões da antracnose do feijoeiro com o aumento da temperatura de incubação, numa faixa de 28 a 32 ${ }^{\circ} \mathrm{C}$. Tais observações enfatizaram a sensibilidade de $C$. lindemuthianum a altas temperaturas em função de danos na estrutura e fisiologia de conídios e apressórios reprimindo seu crescimento em temperatura elevada. Resultados semelhantes foram confirmados por Pria et al. (2003) referentes à não ocorrência de infecção por $C$. lindemuthianum em plantas de feijão, inoculadas e incubadas em ambiente com temperatura acima de $33^{\circ} \mathrm{C}$.

$\mathrm{Na}$ análise de variância tanto para a incidência quanto para a severidade houve interação entre os tratamentos e as épocas de avaliação $(\mathrm{P} \leq 0,01)$.
Com relação às épocas de avaliação para a incidência e a severidade da antracnose, as parcelas com e sem fungicida apresentaram resposta linear com uma maior taxa de progresso da doença nas parcelas sem fungicida (Figuras 2 e 3). Silva (1997) também encontrou uma função linear para descrever a severidade da doença.

O controle da doença foi estatisticamente superior nas parcelas com pulverização de fungicida comparadas àquelas sem utilização de fungicida e esse resultado se comprova pelos valores médios de área abaixo da curva de progresso da severidade da doença equivalentes a 2.216 e 3.841 , respectivamente. Vale ressaltar que o período onde se registra a maior diferença entre os tratamentos (Figura 3), coincidiu com o período de maior severidade da antracnose (Figura 1B).

A

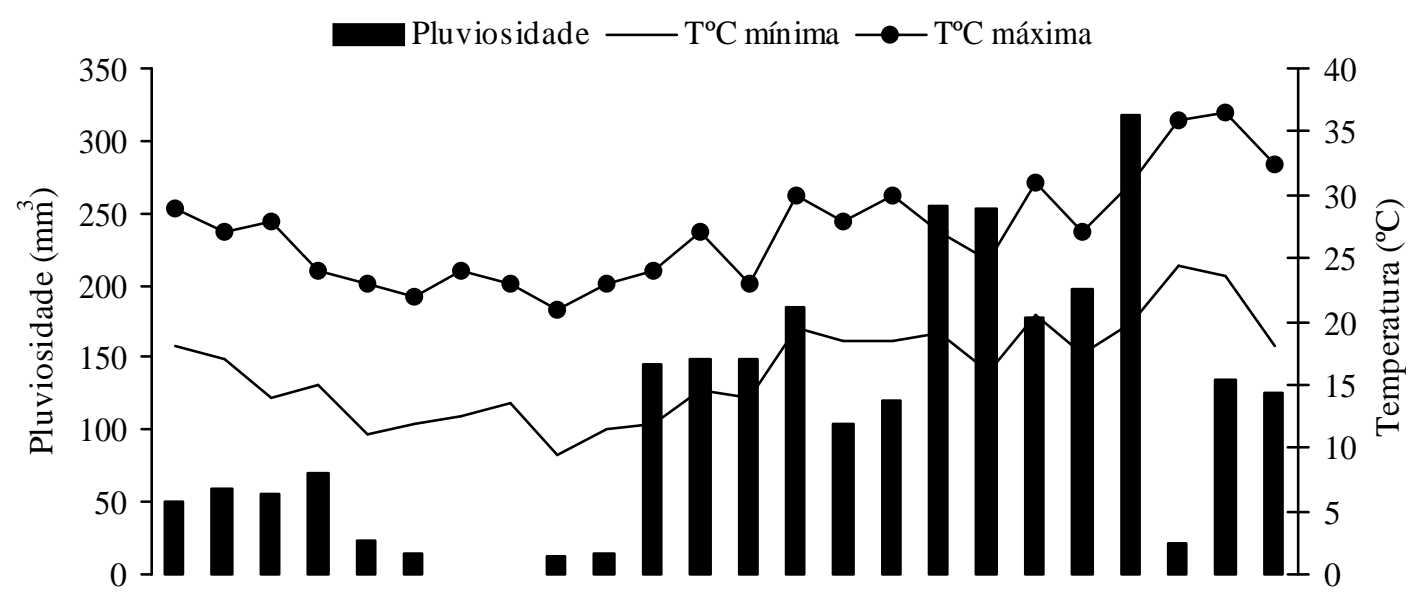

B

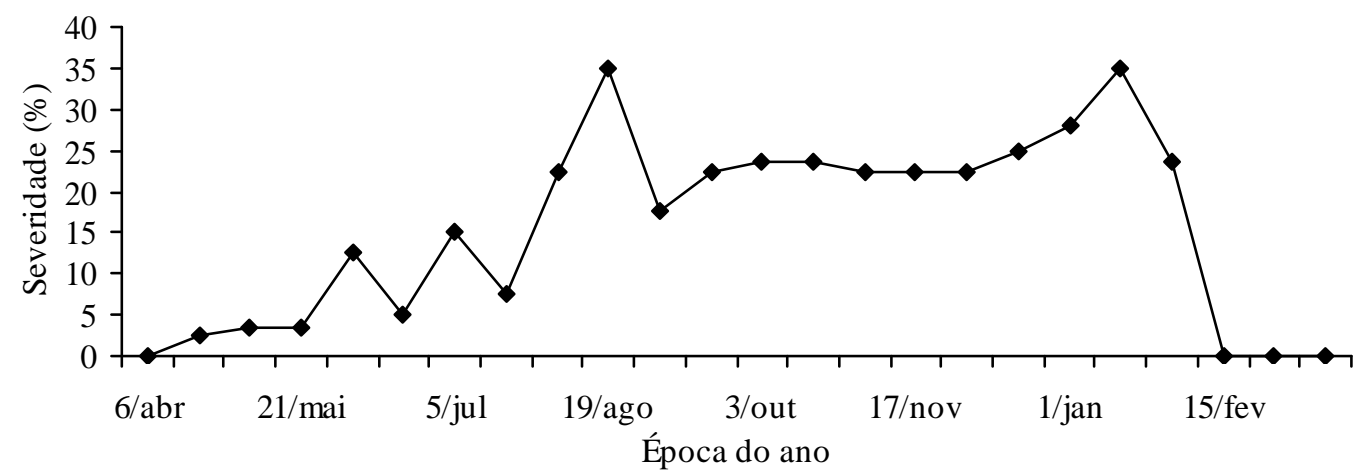

Figura 1 - Pluviosidade média e temperaturas máxima e mínima (A) e curva de progresso da severidade da antracnose (Colletotrichum lindemuthianum) do feijoeiro comum (média de quatro repetições), em diferentes épocas de semeadura (B), no período 1996/97. 


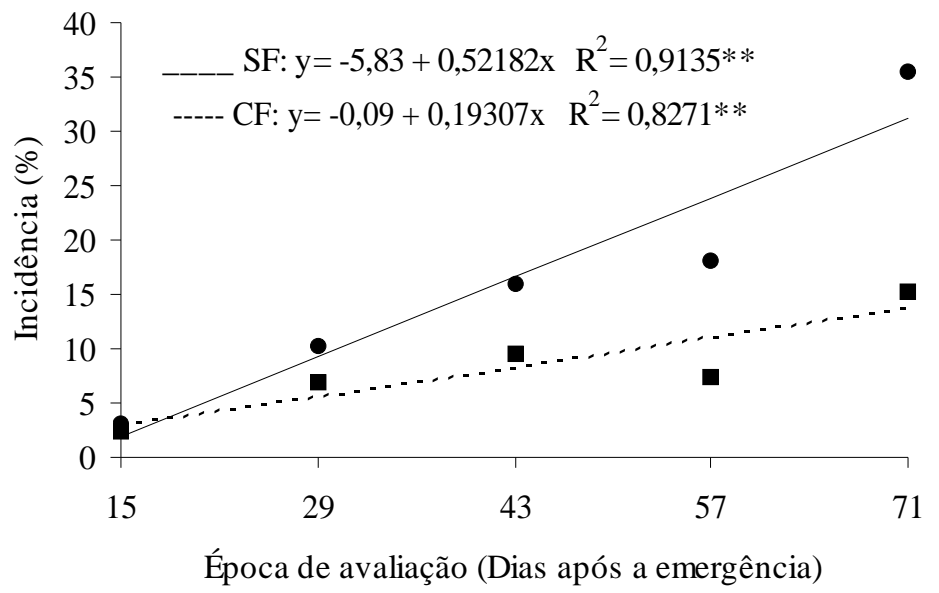

Figura 2 - Progresso da incidência da antracnose (Colletotrichum lindemuthianum) do feijoeiro comum em cinco épocas de avaliação, com (CF) e sem fungicida (SF), no período 1996/97. Cada ponto representa média de quatro repetições.

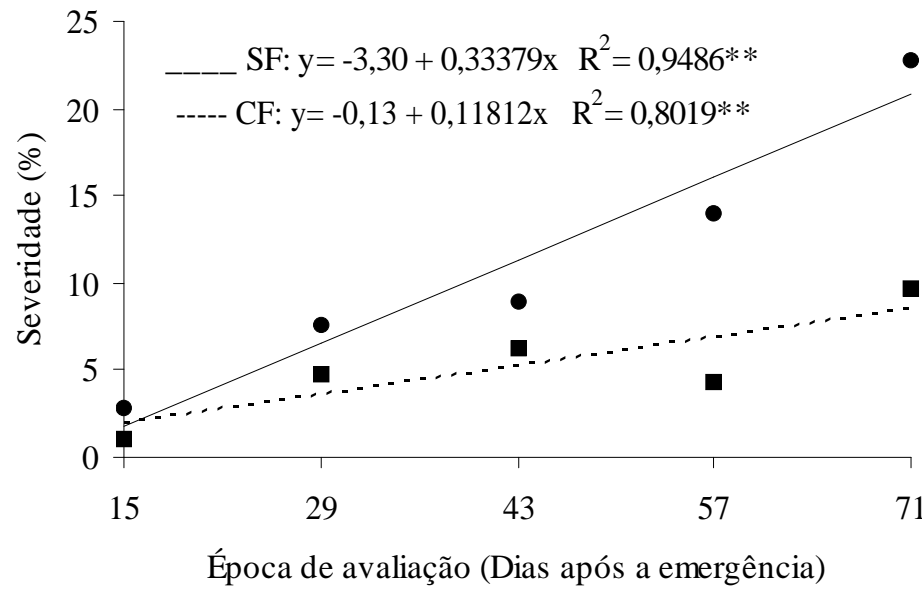

Figura 3 - Progresso da severidade da antracnose (Colletotrichum lindemuthianum) do feijoeiro comum em cinco épocas de avaliação, com (CF) e sem fungicida (SF), no período 1996/97. Cada ponto representa média de quatro repetições.

Com relação ao efeito do fungicida, registrou-se nas parcelas pulverizadas produtividade média de 1006 $\mathrm{Kg} / \mathrm{ha}$, enquanto nas parcelas não pulverizadas a produtividade média foi de $662 \mathrm{Kg} / \mathrm{ha}$, significativamente inferior, confirmando a eficiência da pulverização no controle da antracnose (DARIO et al., 1995; GIANASI et al., 2002; RAVA, 2002). Somente no quinto e décimo nono plantio a produtividade das parcelas sem tratamento aproximou-se das parcelas tratadas (Figura 4). Houve um período compreendido entre o sexto e o décimo primeiro plantio, correspondente aos meses de junho a setembro, que a produtividade obtida com o tratamento químico foi, em média, 52,5\% superior ao tratamento sem fungicida. Resultados similares foram obtidos por Oliveira (2003), registrando produtividade de feijoeiros 59\% superior à testemunha não pulverizada com fungicidas. Além de reduzir a quantidade de doença e as perdas na produtividade, a pulverização com a mistura Tiofanato metílico + Clorotalonil é uma prática recomendada para evitar o surgimento de resistência a fungicidas, esse sério problema que pode por em risco o controle fitossanitário, em contraste com o uso contínuo de um único princípio ativo que pode promover a seleção de fungos resistentes. 


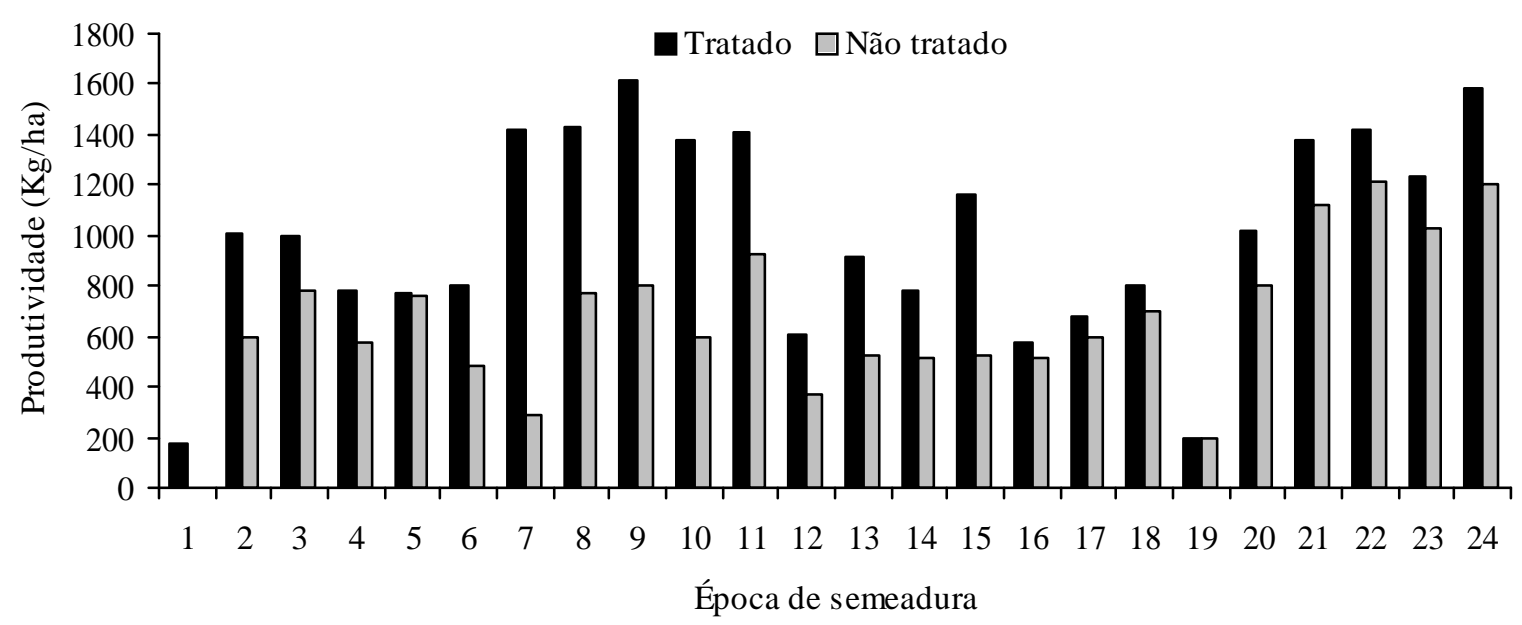

Figura 4 - Produtividade média do feijoeiro cultivar Carioca em 24 plantios, compreendidos entre 04/96 e 03/97, nas parcelas com e sem tratamento fungicida, em Lavras, MG.

A correlação negativa da severidade da antracnose com o rendimento de grãos foi significativa para as avaliações aos 15, 29, 57 e 71 d.a.e., registrando-se coeficientes de $-0,36,-0,50,-0,61$ e $-0,63$, respectivamente. Para as avaliações aos 43 d.a.e. o coeficiente de correlação não foi significativo. A alta severidade na maioria das épocas de cultivo do feijoeiro foi caracterizada como fator condicionante de reduções na produção da cultura. Pompeu et al. (1992) também evidenciaram a importância dessa doença, em decorrência de sua constante presença em diversas épocas de plantio influenciar na redução do rendimento da cultura.

Os resultados obtidos no presente estudo demonstraram que a elevação da temperatura, acima de 25 ${ }^{\circ} \mathrm{C}$ a partir de setembro, associada às freqüentes chuvas que caíram nesse período foram condições preponderantes para a curva de progresso da antracnose nas condições desse experimento. A maior severidade registrada nas parcelas sem fungicidas resultou em redução de até $52 \%$ na produtividade, confirmando as perdas ocorridas no feijoeiro em condições ambientais favoráveis a maiores taxas de progresso da antracnose (DHINGRA et al., 1986; HAVEY et al., 1988).

\section{CONCLUSÕES}

Não houve ocorrência da antracnose nos meses de fevereiro a março de 1997.

A severidade da doença correlacionou-se negativamente com a temperatura máxima e mínima e, positivamente, com a umidade relativa do ar máxima aos 43 e 57 dias, após a emergência.

A pulverização com Tiofanato metílico + Clorotalonil proporcionou menor severidade da doença e maior produção.

Houve correlação negativa entre severidade da doença e a produção aos 15, 29, 57 e 71 dias, após a emergência.

\section{REFERÊNCIAS BIBLIOGRÁFICAS}

AGRIANUAL. Anuário da agricultura brasileira. São Paulo: FNP Consultoria e Comércio, 2004. 562 p.

ARAYA, C.; DHINGRA, O. D.; KUSHALAPPA, A. C. Relacion entre la incidência de Colletotrichum lindemuthianum en el campo y transmission del patógeno por la semilla de frijol (Phaseolus vulgaris). Phytopathology, Saint Paul, v. 75, n. 8, p. 1175-1185, 1987.

BERGAMIN FILHO, A.; LOPES, D. B.; AMORIM, L.; GODOY, C. V. Avaliação de danos causados por doenças de plantas. Revisão Anual de Patologia de Plantas, Passo Fundo, v. 3, p. 133-184, 1995.

CAMPBELL, C. L.;MADDEN, L. V.Introduction to plant disease epidemiology. New York: J. Wiley \& Sons, 1990. 532 p.

CHAVES, G. La antracnosis. In: SCHWARTZ, H. F.; GALVEZ, G. E. Problemas de producción del frijol. Cali: Centro internacional de agricultura tropical, 1980. p. 37-53. 
DARIO, G. J. A.; DARIO, P. W.; VINCENZO, M. C. V. Avaliação do fungicida (Hexconazole + Chlorothalonil) no controle da antracnose (Colletotrichum lindemuthianum) ocorrente na cultura do feijão (Phaseolus vulgaris). Summa Phythopatologica, Jaguariúna, v. 21, p. 54-54, 1995. Suplemento. Resumo.

DHINGRA, O. D.; FERNANDEZ, C. M. A.; KUSHALAPPA, A. C. Lack of relationship between field incidence of bean antracnose and production of seeds transmiting Colletotrichum lindemuthianum. Fitopatologia Brasileira, Brasília, v. 11, n. 1, p. 95-101, 1986.

EMPRESA BRASILEIRA DE PESQUISA AGROPECUÁRIA. Programa nacional de pesquisa em feijão. Brasília, DF, 1981. 117 p.

GIANASI, L.; FERNANDES, N.; LOURENÇO, S. A.; HASSUIKE, J. T.; BERGAMIN FILHO, A. Relações entre doença, área foliar sadia e produção no patossistema feijoeiro - Colletotrichum lindemuthianum (Sacc. \& Magn.) Scrib. Revista Ciência e Agrotecnologia, Lavras, v. 16, n. 1, p. 99-107, 2002.

HALL, R. Compedium of bean diseases. Saint Paul: APS, 1994. 73 p.

HAVEY, M. J.; FARIA, J. C.; MAXWELL, D. P.; HAGEDORN, D. J. Partial resistance to anthracnose in Brazilian land races of dry beans shows race specificity. Euphytica, Wageningen, v. 39, p. 167-174, 1988.

NUNES, W. M. C.; BERGAMIN FILHO, A. Avaliação dos danos causados pela antracnose (Colletotrichum lindemuthianum) do feijoeiro. Fitopatologia Brasileira, Brasília, v. 21, n. 4, p. 436-442, 1996.

OLIVEIRA, S. H. F. Novos fungicidas e programas de pulverizações para o controle da antracnose e da mancha angular do feijoeiro. Summa Phythopatologica, Botucatu, v. 29 , n. 1 , p. $45-48,2003$.
POMPEU, S. S.; DUDIENAS, C.; ITO, M. F. Linhagens de feijoeiro resistentes ao fungo da antracnose (Colletotrichum lindemuthianum), obtidas pelo uso dos genes Mex2 e Mex3. Summa Phythopatologica, Jaguariúna, v. 18, n. $3 / 4$, p. 220-226, 1992.

PRIA, D. M.; AMORIM, L.; BERGAMIN FILHO, A. Quantificação de componentes monocíclicos da antracnose do feijoeiro. Fitopatologia Brasileira, Brasília, v. 28, n. 4, p. 401-407, 2003.

RAHE, J. E.; KUÆ, J. Metabolic nature of the infection limiting effect of heat on bean anthracnose. Phytopathology, Saint Paul, v. 60, n. 6, p. 1005-1009, 1970.

RAVA, C. A. Eficiência de fungicidas no controle da antracnose e da mancha angular do feijoeiro comum. Summa Phythopatologica, Botucatu, v. 28, n. 1, p. 65-69, 2002.

RAVA, C. A.; PURCHIO, A. F.; SARTORATO, A. Caracterização de patótipos de Colletotrichum lindemuthianum que ocorrem em algumas regiões produtoras de feijoeiro comum. Fitopatologia Brasileira, Brasília, v. 19, n. 2, p. 167-172, 1994.

SCHWARTZ, H. F.; GAlVEZ, G. E. Problemas de producción del frijol: enfermedades, insectos, limitaciones edáficas e climáticas de Phaseolus vulgaris. Cali: Centro Internacional de Agricultura Tropical, 1980. 424 p.

SILVA, M. B. da. Área foliar verde para estimar danos causados por doenças do feijão comum. 1997. $51 \mathrm{f}$. Tese (Doutorado em Fitopatologia) - Universidade Federal de Viçosa, Viçosa, 1997.

TALAMINI, V. Progresso espacial e temporal da antracnose a partir de diferentes níveis de inóculo inicial em sementes de feijoeiro. 2003. 72 p. Tese (Doutorado em Fitopatologia) - Universidade Federal de Lavras, Lavras, 2003. 